\title{
A Rapid Method for Constructing Multiply Marked Strains of Bacillus subtilis
}

\author{
By PATRICK J. PIGGOT AND HERMINIA DE LENCASTRE* \\ Division of Microbiology, National Institute for Medical \\ Research, Mill Hill, London, NW7 $1 A A$
}

(Received 20 January 1978)

\section{INTRODUCTION}

Strains carrying multiple mutations greatly aid genetic analysis. A problem in Bacillus subtilis genetics has been the difficulty of constructing such multiply marked strains. Most commonly, non-selective markers are introduced by transformation with high concentrations of DNA. Under these circumstances unlinked and unselected donor markers are transferred to the selected transformants at low frequency (this phenomenon has been termed congression; Nester, Schafer \& Lederberg, 1963). Any one unselected marker may be present in up to $5 \%$ of the selected transformants. In this way different markers can be introduced into the recipient strain. The limitation is that the selective character is lost, preventing repetition of the process. Takahashi \& Ikeda (1968) have described a way to overcome this limitation by alternatively selecting and screening for $e r y^{\mathrm{R}} s t r^{\mathrm{S}}$ and $e r y^{\mathbf{S}} s t r^{\mathrm{R}}$ transformants (the str and ery loci are linked by transformation). These particular markers are somewhat awkward to work with and are difficult to remove from the final strain. The method could presumably be employed with other pairs of linked markers in repulsion crosses, but still has the disadvantage of having to construct the initial donor strains. The method has not been widely used. We describe here an alternative procedure which offers a considerable advantage as special donor strains need not be constructed.

We have been studying the relationship of competence to sporulation in B. subtilis. We have found that it is possible to transform asporogenous mutants in a sporulation medium (that of Ramaley \& Burden, 1970) so that they are able to form heat-resistant spores. This confirms the finding by Erickson \& Young (unpublished results quoted by Young \& Wilson, 1972) of transformation in this system. For certain mutants, some of the transformed recipients form heat-resistant spores (selected by heating to $85^{\circ} \mathrm{C}$ for $20 \mathrm{~min}$ ) and yet the colonies that grow up from these spores are genetically asporogenous. The reason for the anomalous result is being investigated. It is thought possible that the chromosome of the mother cell, but not of the forespore, is transformed and that this is sufficient for the forespore to develop into a heat-resistant spore. Whatever the explanation, the surviving asporogenous bacteria can be subjected to repeated cycles of this transformation/sporulation/heat treatment procedure. Using high concentrations of DNA, it is possible to introduce a series of unselected markers into the recipient by such repeated cycles.

\section{METHODS}

Strains. The bacterial strains used were all derivatives of Bacillus subtilis 168. They were: 34.1 , spoOA34 phe-12; 91, spoVB91 trpC2 (Hranueli, Piggot \& Mandelstam, 1974; Piggot \& Coote, 1976); MB8, hisA1 (Piggot, 1973); M22, purA16 leu-8 metB5 ile-1; BD68, argC4 ura-26 leu-2 (Karamata \& Gross, 1970). Strains were stored as freeze-dried cultures. The phenotypes corresponding to the different symbols are: unable to

* Permanent address: Universidade Nova de Lisboa, Instituto Gulbenkian de Ciência, Portugal. 
sporulate, spo; requirement for arginine, arg; for histidine, his; for isoleucine, ile; for leucine, leu; for methionine, met; for phenylalanine, phe; for purine, pur; for tryptophan, trp; for uracil, ura.

Sporulation/transformation system. The system was based on that described by Ramaley \& Burden (1970) for replacement sporulation. The media contained, in 1 litre final volume, adjusted to $\mathrm{pH} 7 \cdot 2: 0.33 \mathrm{ml} 85 \%$ $\mathrm{H}_{3} \mathrm{PO}_{4} ; 1 \mathrm{~g} \mathrm{MgSO}_{4} .7 \mathrm{H}_{2} \mathrm{O} ; 0.4 \mathrm{~g} \mathrm{NaCl} ; 0.4 \mathrm{~g} \mathrm{KCl} ; 25 \mathrm{mg} \mathrm{Fe}\left(\mathrm{NH}_{4}\right)_{2}\left(\mathrm{SO}_{4}\right)_{2} .6 \mathrm{H}_{2} \mathrm{O} ; 10 \mathrm{mg} \mathrm{CaCl} 2 ; 6 \mathrm{mg}$ $\mathrm{MnSO}_{4} \cdot \mathrm{H}_{2} \mathrm{O}$. In addition the growth medium contained $20 \mathrm{~mm}$-glucose and $50 \mathrm{~mm}$-glutamate, while the sporulation medium contained $10 \mathrm{~mm}$-glutamate. Solutions of $\mathrm{MgSO}_{4}, \mathrm{CaCl}_{2}$, glucose and glutamate were sterilized separately and added to a sterile solution of the other salts shortly before the medium was required. Where necessary, media were supplemented with: adenine sulphate, $20 \mu \mathrm{g} \mathrm{ml}^{-1}$; uracil, $20 \mu \mathrm{g} \mathrm{ml}^{-1}$; phenylalanine, $100 \mu \mathrm{g} \mathrm{ml}^{-1}$; tryptophan, $10 \mu \mathrm{g}$ (ml growth medium) $)^{-1}$ or $1 \mu \mathrm{g}$ (ml sporulation medium) ${ }^{-1}$; other amino acids, $100 \mu \mathrm{g}(\mathrm{ml} \text { growth medium })^{-1}$ or $10 \mu \mathrm{g}(\mathrm{ml} \text { sporulation medium })^{-1}$. The necessity for these latter shifts down was not established.

Bacteria were grown in growth medium at $37^{\circ} \mathrm{C}$ to a bacterial density of approximately $0.10 \mathrm{mg} \mathrm{dry} \mathrm{wt} \mathrm{ml} \mathrm{m}^{-1}$. The bacteria were harvested by centrifugation and resuspended in an equal volume of prewarmed sporulation medium and again incubated at $37^{\circ} \mathrm{C}$ with vigorous aeration. DNA (prepared by the method of Marmur, 1961) was added at the time of resuspension to a concentration of $5 \mu \mathrm{g} \mathrm{ml}^{-1}$. After 16 to $20 \mathrm{~h}$ in the sporulation medium, cultures were heated to $85^{\circ} \mathrm{C}$ for $20 \mathrm{~min}$ in order to select heat-resistant spores, and survivors were scored by incubating samples on nutrient agar (Difco) plates for $48 \mathrm{~h}$ at $42^{\circ} \mathrm{C}$. At this time, Spo ${ }^{+}$and $\mathrm{Spo}^{-}$ colonies were distinguishable by morphology and pigmentation; this distinction was confirmed by examination with a phase-contrast microscope. Growth requirements of transformants were tested by picking colonies and streaking on to minimal agar (Piggot, 1973) with appropriate supplements. Transformants that had acquired a new auxotrophic requirement were tested in detail.

\section{RESULTS AND DISCUSSION}

Bacillus subtilis mutant 91 (spoVB91 trpC2) was transformed with spoVB⿱一土 phe-12 DNA (from strain 34.1), the culture was given the opportunity to sporulate then heat-treated, and survivors were identified as described in Methods. Approximately equal numbers of $\mathrm{Spo}^{+}$ and $\mathrm{Spo}^{-}$colonies were obtained (Table 1). No survivors of either type were obtained when the DNA had previously been degraded by DNAase, when DNA carrying the spoVB91 mutation was used, or when no DNA was used. Of $88 \mathrm{Spo}^{-}$transformants tested, 10 were found to have become phenylalanine auxotrophs. One of these, SL11, was used to build up a series of multiply marked auxotrophs (Table 1). In this way, in four successive transformations up to six distinct auxotrophic mutations were introduced into strain 91 without loss of the original spoVB91 and $\operatorname{trp} C 2$ mutations.

Should a $\mathrm{Spo}^{+}$strain be required, the spoVB91 mutation can be readily removed by an additional transformation. Alternatively, in a series of crosses building up a particular strain, the $\mathrm{Spo}^{+}$transformant could be tested for the appropriate auxotrophic requirements at the final stage.

A feature of the system was the high frequency of congression. For example, when SL20 was transformed by DNA from M22, 64 out of 216 transformants tested gained at least one auxotrophic requirement. Amongst these, 24 gained purA16, 28 metB5, 22 leu- 8 and 16 ile-1 indicating a congression frequency of approximately $10 \%$ for each marker. (No requirements were gained that had not been present in the donor.) The high frequency of congression necessarily meant that many of the transformants which gained donor markers also lost recipient markers; such transformants are not listed in Table 1.

Herminia de Lencastre was supported in part by a fellowship from the Instituto Gulbenkian de Ciência. 


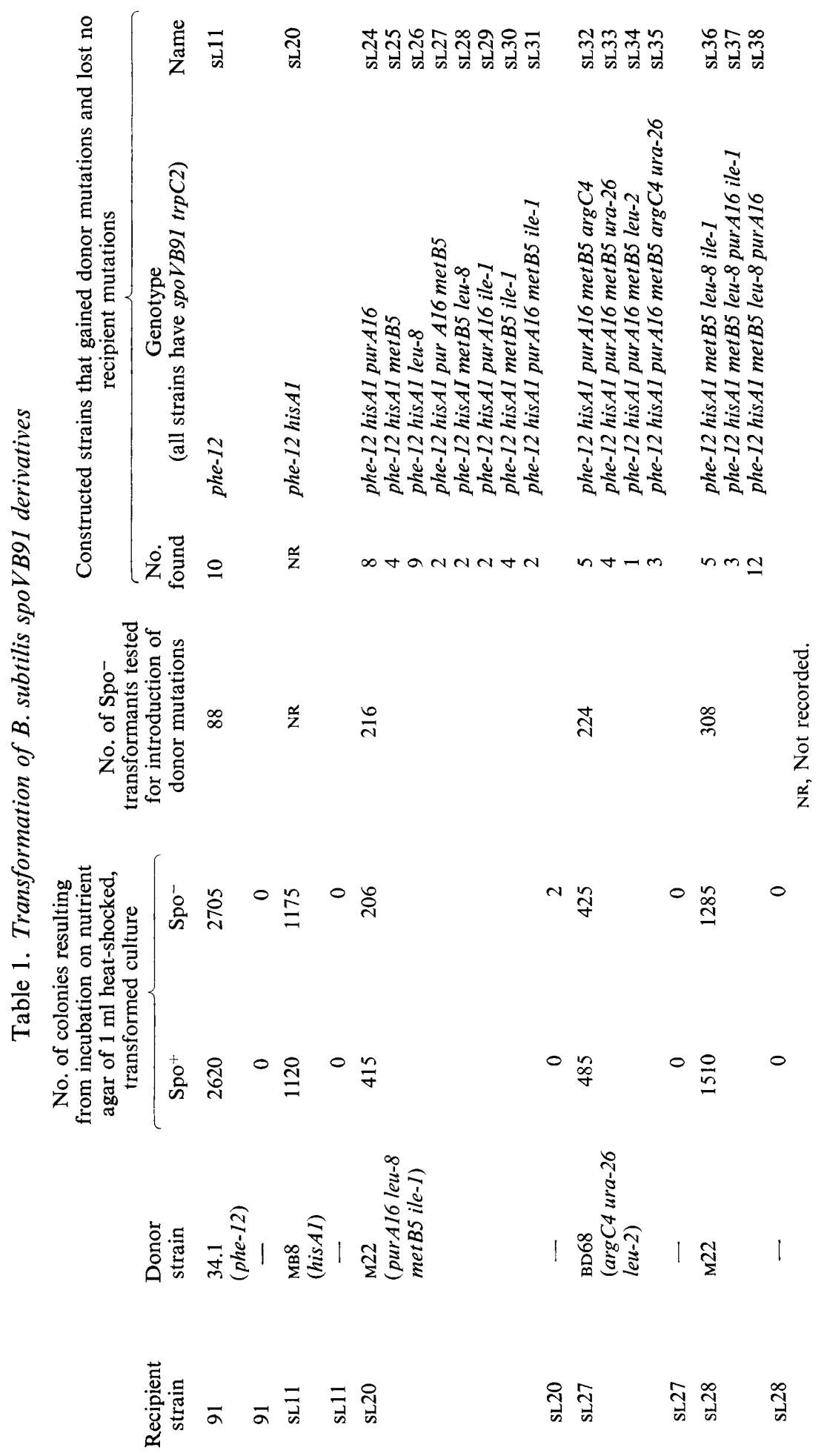




\section{REFERENCES}

Hranueli, D., Piggot, P. J. \& Mandelstam, J. (1974). Statistical estimate of the total number of operons specific for Bacillus subtilis sporulation. Journal of Bacteriology 119, 684-690.

Karamata, D. \& Gross, J. D. (1970). Isolation and genetic analysis of temperature-sensitive mutants of B. subtilis defective in DNA synthesis. Molecular and General Genetics 108, 277-287.

MARMUR, J. (1961). A procedure for the isolation of deoxyribonucleic acid from micro-organisms. Journal of Molecular Biology 3, 208-218.

Nester, E. W., Schafer, M. \& Lederberg, J. (1963). Gene linkage in DNA transfer: a cluster of genes concerned with aromatic biosynthesis in Bacillus subtilis. Genetics 48, 529-551.

Piggot, P. J. (1973). Mapping of asporogenous mutations of Bacillus subtilis: a minimum estimate of the number of sporulation operons. Journal of Bacteriology 114, 1241-1253.
Piggot, P. J. \& Coote, J. G. (1976). Genetic aspects of bacterial endospore formation. Bacteriological Reviews 40, 908-962.

RAMALEY, R. F. \& BURden, L. (1970). Replacement sporulation of Bacillus subtilis 168 in a chemically defined medium. Journal of Bacteriology 101, 1-8.

TAKaHASHI, H. \& IKeDA, Y. (1968). A simple method for obtaining multiple marked strains of Bacillus subtilis. Journal of General and Applied Microbiology 14, 451-452.

Young, F. E. \& Wilson, G. A. (1972). Genetics of Bacillus subtilis and other Gram-positive sporulating Bacilli. In Spores, vol. V, pp. 77-106. Edited by H. O. Halvorson, R. Hanson and L. L. Campbell. Washington, D.C.: American Society for Microbiology. 